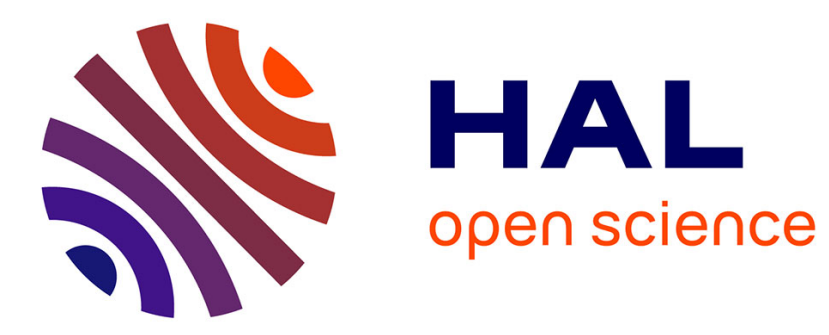

\title{
A small portable detector head using mis-contacted CdTe for X-ray spectrometry
}

\author{
P. Eichinger, J. Kemmer
}

\section{To cite this version:}

P. Eichinger, J. Kemmer. A small portable detector head using mis-contacted CdTe for X-ray spectrometry. Revue de Physique Appliquée, 1977, 12 (2), pp.339-341. 10.1051/rphysap:01977001202033900 . jpa-00244169

HAL Id: jpa-00244169

https://hal.science/jpa-00244169

Submitted on 1 Jan 1977

HAL is a multi-disciplinary open access archive for the deposit and dissemination of scientific research documents, whether they are published or not. The documents may come from teaching and research institutions in France or abroad, or from public or private research centers.
L'archive ouverte pluridisciplinaire HAL, est destinée au dépôt et à la diffusion de documents scientifiques de niveau recherche, publiés ou non, émanant des établissements d'enseignement et de recherche français ou étrangers, des laboratoires publics ou privés. 


\title{
A SMALL PORTABLE DETECTOR HEAD USING MIS-CONTACTED CdTe FOR X-RAY SPECTROMETRY
}

\author{
P. EICHINGER \\ Institut für Festkörpertechnologie, Paul-Gerhardt-Allee 42, 8000 München 60, Germany \\ J. KEMMER \\ Physik Department der Technischen Universität, München, 8046 Garching, Germany
}

\begin{abstract}
Résumé. - On décrit les propriétés de détecteurs nucléaires au tellurure de cadmium sur lesquels le contact redresseur est assuré par un film isolant de mylar rendu conducteur en surface par un dépôt métallique. Une tête de détection comportant un tel compteur d'épaisseur $2 \mathrm{~mm}$ et de diamètre $10 \mathrm{~mm}$, refroidi par un élément Peltier a été réalisé. Ses performances seront discutées. Dans les conditions optimales une résolution en énergie de $2 \mathrm{keV}$ a été atteinte pour des photons de $90 \mathrm{keV}$, un rapport pic photoélectrique : hauteur de la distribution Compton de $2: 1$ a été relevé pour des rayonnements $\gamma$ de $662 \mathrm{keV}$. Notons que la plupart des spectromètres présentent un piégeage important de trous, ce qui dégrade les performances de détection de ces dispositifs.
\end{abstract}

\begin{abstract}
The technique of applying thin insulating layers (mylar) as blocking contacts for semiconductor radiation detectors is discussed. A versatile head consisting of a $2 \mathrm{~mm}$ thick, $10 \mathrm{~mm}$ diameter CdTe crystal cooled by a miniature Peltier element has been realized on this principle. Its performance is discussed. For the best material, a FWHM of $2 \mathrm{keV}$ was achieved for $90 \mathrm{keV} \gamma$-rays and a peak to Compton ratio of $2: 1$ for $662 \mathrm{keV}$. However, most of the crystals show severe hole trapping, leading to poorer results.
\end{abstract}

1. Introduction. - Since this conference is completely devoted to CdTe-detectors it is not necessary to discuss the promising properties and the implications of this material for the spectroscopy of gamma rays and $\mathrm{X}$-rays. Instead an arrangement will be presented which has already found applications in X-ray detection. This spectrometer is based on a somewhat exotic method of applying electrical contacts to the material - the insulator method [1] - in order to obtain high collecting fields with minimum injection currents. The principle of this process and its application to $\mathrm{CdTe}$ and $\mathrm{CdS}$ has already been published [2, 3], but because of the many misunderstandings following this publication, we feel justified to discuss it here again. Following this, the spectrometer will be described in detail together with its characteristics, actual and possible applications.

2. MIS-contacts. - Blocking contacts on nearly intrinsic CdTe which are capable to sustain electrical field strengths in the order of $10^{4} \mathrm{Vcm}^{-1}$ are difficult to obtain with evaporated metals. An alternative solution for blocking contacts is obviously the insertion of thin insulating layers between the pure crystal surface and the metallic electrodes as it is shown in figure 1. The result is a capacitive coupling between the semiconductor and the external circuit. When high voltage is applied, the semiconductor gets in a non-equilibrium

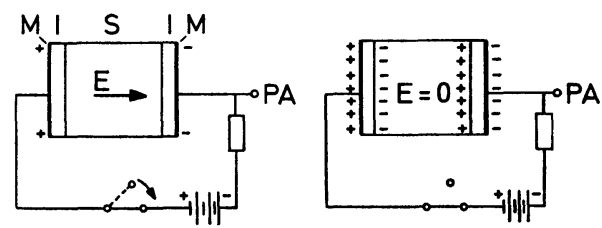

FIG. 1. - Principle of operation of capacitive contacts on a detector : shortly after applying bias (left) and in equilibrium (right).

state with an electric field across it, which is equal to the applied voltage divided by the crystal thickness, if the insulating layer is sufficiently thin. The arrangement can act as a detector : Free carrier pairs generated by absorbed radiation are separated by the electric field - thereby a current pulse is induced in the external circuit. The free carriers accumulate at the interfaces and this results in a gradual reduction of the electric field. Thermally generated carriers in the bulk and at the surfaces have the same effect. Finally the electric field will vanish, making detector operation impossible. A reactivation of the arrangement is very simply performed by shorting the electrodes: An opposite electric field will be generated by the charge layers at the interfaces and the charges, if they are free to move, are driven into the bulk where they recombine. Thereafter, voltage can be applied again. In the case of interface trapping the opposite field, after shorting the 
electrodes, will persist and can be removed by illuminating the crystal. Alternatively, detector operation is possible with no external bias during counting, i.e. with the internal polarization field alone. Having established the principle of the method, the most important question concerns the decay time of the electric field : how many carrier pairs can be separated until the field vanishes ? This number is expressed by the following relation :

$$
N=\frac{C_{\mathrm{i}} U}{2 e},
$$

where $e$ is the electron charge, $C_{\mathrm{i}}$ the capacitance of one of the MIS contact at thermal equilibrium, i. e. field free semiconductor. This number is $10^{14}$ for $1 \mu$ thick insulators having a relative dielectric constant of 3 applied on $1 \mathrm{~cm}^{2}$ contacts at $1000 \mathrm{~V}$ applied voltage. Therefore, approximately $5 \times 10^{9}$ quanta of $100 \mathrm{keV}$ energy could be counted, under the assumption that no other charge generation process is present, e. g. mainly at low temperature. With a thermal generation current of $1 \mathrm{nA}$ it will take about $100 \mathrm{~min}$. to destroy the electrical field. Currents in this order of magnitude can be reached with these capacitive contacts by slight cooling $\left(-10^{\circ} \mathrm{C}\right)$ of the counter. In fact, these numbers are indicative, since for sufficient constancy of carrier collection, only a small variation of the field strength, e. g. $10 \%$, can be tolerated. Therefore, the usual working time has to be reduced, but after this period, reactivation can be performed in a very short time by shorting the electrodes, eventually combined with a light flash onto the counter.

\section{Construction of the detector head and performance.}

- The spectroscopy system constructed on the basis of the MIS-contact principle consists of a detector head of $15 \mathrm{~cm}$ length and $6 \mathrm{~cm}$ diameter which is connected by a several meter long cable to an electronic unit combining the power supply for the detector head, a reactivation circuity and the main amplifier (shaping time $2 \mu$ s nad $4 \mu \mathrm{s}$ ). This unit occupies two sections of a $19^{\prime \prime}$ NIM-BIN. A detailed cross-sectional schematic of the detector head is shown in figure 3. The detector is a $10 \mathrm{~mm}$ diameter, about $2 \mathrm{~mm}$ thick CdTe slice delivered by RMD (premium choice material). It is mounted between $3.5 \mu$ thick mylar foils (one side aluminized) on the cold side of a miniature peltier cooler $(2 \mathrm{~W}$ pumping power, to give a detector temperature of $\left.-10^{\circ} \mathrm{C}\right)$. A $0.5 \mathrm{~mm}$ thick sapphire rod is inserted between the cooler and the detector to make decoupling of the preamplifier possible. The heat generated by the peltier element is carried away by the mounting base plate and distributed by cooler rips along the side of the head. Further components of the detector head include a dc-coupled chargesensitive FET-preamplifier, a REED-relay to perform the switching for the reactivation of the electric field and as GaAs-LED which shines light onto the detector

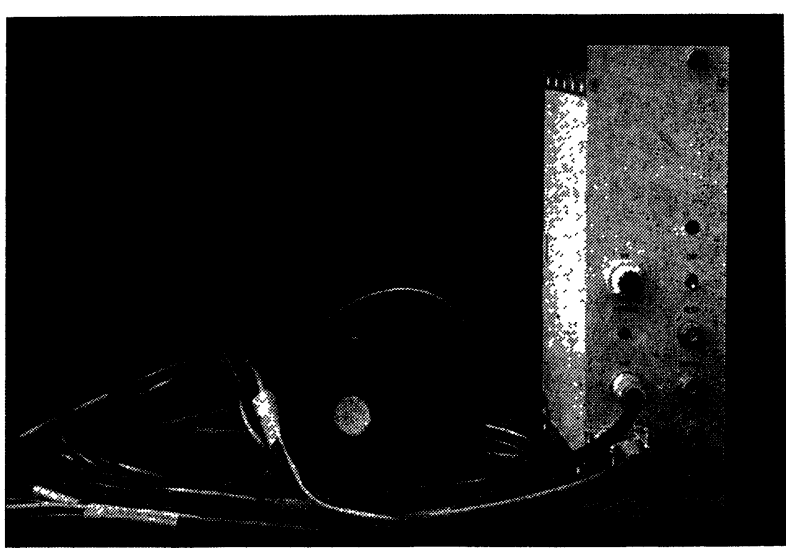

FIG. 2. - Detector head with control and power supply unit.

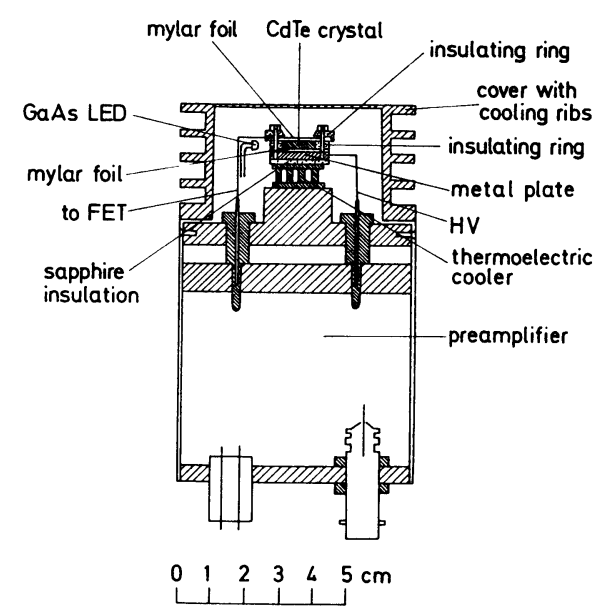

FIG. 3. - Schematic drawing of the detector head.

when the electrodes are shorted. The detector housing is filled with nitrogen at slightly elevated pressure, the entrance window is of beryllium. Figure 2 is a photograph of the system including the reactivation and power supply circuitry.

Before mounting, the CdTe slice is etched in an aged bromine-methanol solution and rinsed in methanol. Typically, the operating bias voltage for the detector is $1000 \mathrm{~V}$, with the negative electrode towards the entrance window, to improve the contribution of the collected electrons to the current pulse. When cooled at $-10^{\circ} \mathrm{C}$, more than 30 s counting time have been found possible, without apparent degradation of the energy resolution of the device. The reactivation cycle for the collecting field is performed automatically after a preset time and takes less than $2 \mathrm{~s}$, resulting in a total dead time of less than $5 \%$. Under these experimental conditions, the results we obtained with the best device have been the following: resolutions (FWHM) respectively of $2.2,2.6$ and $12 \mathrm{keV}$ for $\gamma$-ray energies of 30,60 and $661 \mathrm{keV}$. For the ${ }^{137} \mathrm{Cs}$ photons; a peak to Compton ratio of $2: 1$ and a peak to valley ratio better than 10:1 have been achieved. These results compare favorably with other data published 

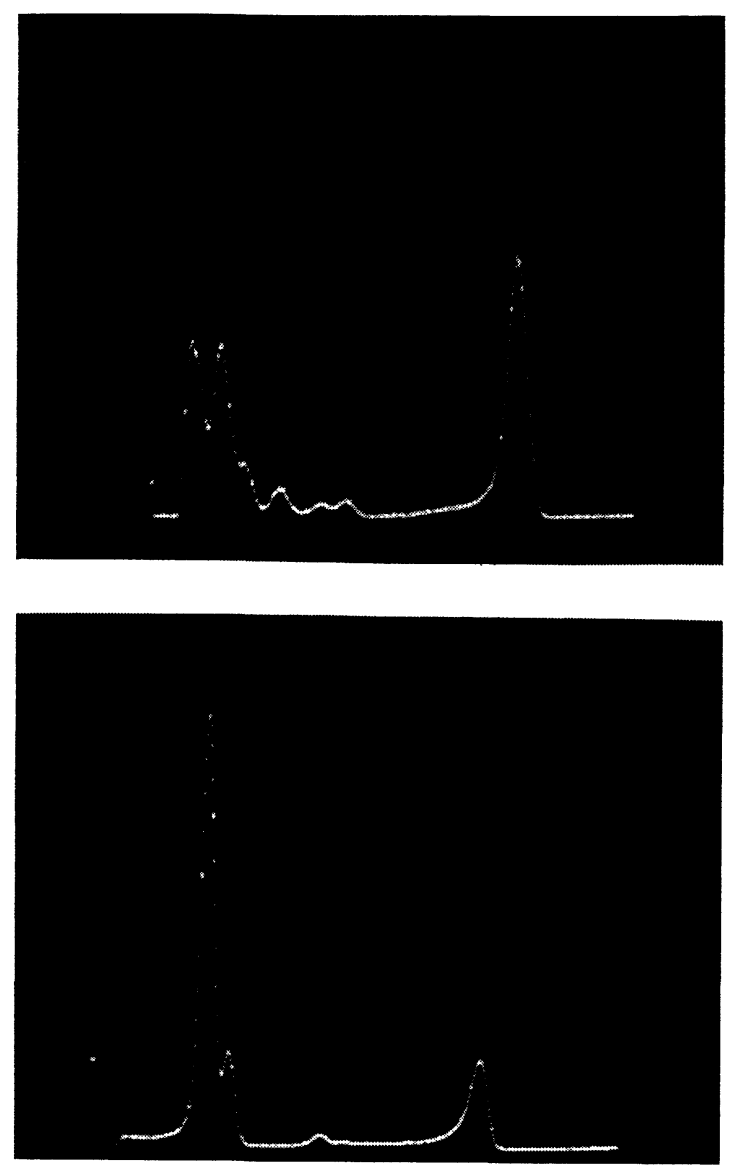

FIG. 4. - Gamma spectra of ${ }^{241} \mathrm{Am}(14,18$ and $60 \mathrm{keV}$, top) and ${ }^{13} 3 \mathrm{Ba}(32,36$ and $80 \mathrm{keV}$, bottom). on such large counters. As an illustration, figure 4 shows the gamma-ray spectra obtained with ${ }^{241} \mathrm{Am}$ and ${ }^{133} \mathrm{Ba}$ sources, showing that it is possible to distinguish lines separated by only $4 \mathrm{keV}$.

4. Applications. - Up to now the detector has been applied for the spectrometry of X-rays scattered out of the primary beam when a phantom body is irradiated at a given point. The knowledge of the spatial distribution of scattered X-rays is important, because they can do harm to organs which are not intended to be irradiated. An obvious application is the energy calibration of X-ray tubes which is hardly possible using scintillators because of their much poorer energy resolution. An electronic circuitry computing the maximum X-ray energy from the pulseheight distribution without the aid of a multichannel analyzer is presently being developed.

The superiority in energy resolution of CdTe system compared to the scintillator crystal is also of interest for scintigraphic applications since for many radioisotope energies as ${ }^{125} \mathrm{I}$ or ${ }^{197} \mathrm{Hg}$ and especially for $99 \mathrm{~m}$ Tc a $2 \mathrm{~mm}$ thick CdTe crystal gives nearly full absorption. An improvement of the diameter of available crystals would be very useful for this application, although paralleling of detectors is also possible.

Further possible applications are in Mössbauer spectroscopy and material diagnosis like $\mathrm{X}$-ray flurescence when energy resolution requirements can be lowered in favour of the flexibility of the instrument.

\section{References}

[1] Eichinger, P. and KallmanN, H., Z. Naturforsch. 28a (1973) 1888.

[2] Eichinger, P., Halder, N. and Kemmer, J., Nucl. Instrum. and Meth. 117 (1974) 305.

[3] Eichinger, P. and Kallmann, H., Appl. Phys. Lett. 25 (1974) 676. 